\title{
Synthesis of Highly Uniform and Composition-Controlled Gold- Palladium Supported Nanoparticles in Continuous Flow
}

Stefano Cattaneo ${ }^{\mathrm{a}^{*}}$, Sultan Althahban ${ }^{\mathrm{b}}$, Simon J. Freakley ${ }^{\mathrm{a}, \mathrm{c}}$, Meenakshisundaram Sankar $^{\mathrm{a}}$, Thomas Davies ${ }^{\mathrm{a}}$, Qian He $\mathrm{He}^{\mathrm{a}}$, Nikolaos Dimitratos ${ }^{\mathrm{a}}$, Christopher J. Kiely ${ }^{\mathrm{a}, \mathrm{b}}$ and Graham J. Hutchings ${ }^{\mathrm{a},}$,

${ }^{a}$ Cardiff Catalysis Institute, School of Chemistry, Cardiff University, Cardiff, CF10 3AT, United Kingdom.

${ }^{\mathrm{b}}$ Department of Materials Science and Engineering, Lehigh University, 5 East Packer Avenue, Bethlehem, Pennsylvania, PA 18015, USA.

${ }^{c}$ Department of Chemistry, University of Bath, Claverton Down, Bath, BA2 7AY, UK.

*CattaneoS@cardiff.ac.uk; Hutch@cardiff.ac.uk 


\begin{abstract}
The synthesis of supported bimetallic nanoparticles with well-defined size and compositional parameters has long been a challenge. Although batch colloidal methods are commonly used to pre-form metal nanoparticles with the desired size-range in solution, inhomogeneous mixing of the reactant solutions often leads to variations in size, structure and composition from batch-tobatch and even particle-to-particle. Here we describe a millifluidic approach for the production of oxide supported monometallic Au and bimetallic AuPd nanoparticles in a continuous fashion. This optimised method enables the production of nanoparticles with smaller mean sizes, tighter particle size distributions and a more uniform particle-to-particle chemical composition as compared to the conventional batch procedure. In addition, we describe a facile procedure to prepare bimetallic Au@Pd core-shell nanoparticles in continuous flow starting from solutions of the metal precursors. Moreover, the relative ease of scalability of this technique makes the proposed methodology appealing not only for small-scale laboratory purposes, but also for the industrial-scale production of supported metal nanoparticles.
\end{abstract}




\section{INTRODUCTION}

Metal nanoparticles have numerous applications in medicine, electronics, energy, environment, biology and chemistry ${ }^{1-3}$ thanks to their unique magnetic, optical, electronic and chemical properties. ${ }^{4,5}$ Supported bimetallic nanoparticles are especially important in catalysis. ${ }^{6-9}$ Two metals can be effectively mixed together to produce a new alloyed material with physical properties that substantially differ from those of the original constituents and that strongly depend on the final composition and nanoscopic morphology. Two effects can be considered as being responsible for the modification in chemical and physical properties of alloy nanoparticles, namely the so-called ligand and ensemble effects. ${ }^{10}$ The former refers to the electronic interactions between the two metals, such as charge redistribution and changes of the d-band electron structure, while the latter refers to the changes in catalytic properties due to the change in chemical composition at the surface. ${ }^{11-13}$

Among bimetallic nanoparticles, gold-palladium alloys have been extensively studied. ${ }^{14-16}$ For instance, gold-palladium nanoparticles smaller than $10 \mathrm{~nm}$ supported on high surface area oxides are commonly used as heterogeneous catalysts in reactions such as selective oxidations of alcohols ${ }^{17,18}$ and hydrocarbons, ${ }^{19}$ transformation of biomass to fuels and chemicals ${ }^{20-22}$ and the direct synthesis of hydrogen peroxide from its constituent elements..$^{23,24}$

The control over the catalytic properties of these supported metal nanoparticles can be highly sensitive to their diameter, chemical composition and alloy structure. The catalytic hydrogenation of nitroaromatics with monometallic Au catalysts, for example, strongly depends on the total surface area of the metal nanoparticles, with small nanoparticles being more active than larger nanoparticles. ${ }^{25-27}$ Similarly, bimetallic AuPd nanoparticles have shown analogous results in the 
liquid phase oxidation of glycerol, where small particles exhibit higher activity despite being less selective towards glycerate. ${ }^{28}$

Moreover, the synergistic effect between the two metals has been found to strongly affect both activity and selectivity of several liquid and gas phase reactions. ${ }^{29-32}$ In the cinnamaldehyde hydrogenation reaction, for instance, random alloy AuPd particles supported on $\mathrm{TiO}_{2}$ showed a maximum of activity for Au:Pd molar ratios of 1:1, while the selectivity towards the desired product increased with increasing Pd content. ${ }^{33}$ On the other hand, the catalytic performance can also be optimised by formation of core-shell structures, where one metal is selectively deposited on the surface of the nanoparticle. In this way, one can combine the synergistic effect while maintaining the desired surface composition. Au@Pd core-shell nanoparticles, for instance, showed a volcano-like behaviour in the selective oxidation of benzyl alcohol with a maximum in activity at only $10 \%$ of Pd, corresponding to a one atomic layer of $\mathrm{Pd} .^{34}$ It is therefore clear that a catalyst preparation method that allows exquisite control of particle size, metal composition and alloy structure is fundamental for the optimisation of the catalytic performance of these supported nanoparticles.

One promising method for the synthesis of supported metal nanoparticles is the sol-immobilisation method, ${ }^{35}$ where nanoparticles are prepared in solution by chemical reduction of metal precursors and then immobilised onto the support materials. The synthetic procedure consists of five fundamental steps: namely (I) mixing of the metal precursors and reducing agent, (II) fast reduction of metal ions to metallic atoms, (III) nucleation of these insoluble metal atoms, (IV) growth into nanoparticles and finally, (V) deposition of the metallic nanoparticles onto a support material. However, this technique is typically performed in conventional mechanically-stirred batch reactors, where inhomogeneous mixing of the reactants often leads to variance in the 
chemical-physical properties of the resultant nanoparticles. ${ }^{36}$ In fact, this inhomogeneous mixing originates from the formation of microscopic local reaction conditions (such as metal precursors and reducing agent concentration gradients) due to the slow mixing process inherent to mechanical stirring. Consequently, the nucleation and growth steps are not sufficiently separated in time and competition for metal ions between the two parallel processes, leading to polydispersity in nanoparticle size and shape and poor batch-to-batch reproducibility. These complications are even more apparent when two metals are co-reduced, and differences in redox potentials can lead to systematic composition variations from particle-to-particle. Pritchard et al., for example, observed size-dependent composition variations in AuPd nanoparticles stabilised by polyvinyl alcohol (PVA) and deposited on activated carbon: small nanoparticles (ca. $2 \mathrm{~nm}$ ) were consistently $\mathrm{Au}-$ rich while larger particles (ca. $6 \mathrm{~nm}$ ) showed a Pd-rich composition. ${ }^{37}$ All these problems make the synthesis of bimetallic alloy particles with uniform size and composition a highly challenging problem and currently limits the larger scale operation and uptake of this method. ${ }^{38-40}$

To overcome these problems, recent research has employed micro- and milli-fluidic reactors in nanoparticle synthesis. ${ }^{41-46}$ These approaches provide enhanced mixing allowing microscopic control over the reaction conditions; this in turn permits the spatial and temporal separation of the nucleation and growth steps and thus allows the synthesis of smaller metal nanoparticles with narrower size distributions. ${ }^{47,48}$ Despite the numerous reports present in literature regarding the synthesis of monometallic Au nanoparticles in continuous-flow mode, ${ }^{49-55}$ not many studies have focussed their attention on bimetallic AuPd nanoparticles. Nakajima et al., for instance, used a multi-laminar flow micromixer in order to obtain highly monodisperse AuPd clusters. ${ }^{56}$ The bimetal composition, however, was only evaluated with a bulk technique (ICP-AES), therefore it was impossible to establish whether or not the as-synthesised nanoparticles presented consistent 
alloy compositions from particle-to-particle. On the other hand, Grunwaldt and co-workers adopted a different approach, using a series of three cyclone micromixers integrated in a microfluidic chip and high solution flow rates in order to obtain small and monodisperse AuPd alloy nanoparticles. ${ }^{57}$ Although STEM-XEDS analysis showed a homogeneous alloy composition, in-depth XAS analysis revealed the presence of a Au-enriched core and a Pd-rich surface, with some Pd being segregated as small monometallic particles as well. In addition, both studies made use of ad-hoc microfluidic devices that are often difficult to fabricate, expensive and hard to scaleup. ${ }^{53}$ Finally, to the best of our knowledge, the production of Au@Pd core-shell structures in a one-phase micro- or milli-fluidic setup has not been reported to date and we therefore took this key challenge of compositional and morphological control in bimetallics as a starting point in the present study.

In this work, we report the continuous production of $\mathrm{TiO}_{2}$-supported bimetallic AuPd nanoparticles with small mean particle size $(c a .2 \mathrm{~nm})$ and a much-improved composition distribution compared to materials prepared via the conventional sol-immobilisation method. ${ }^{37}$ The continuous method was firstly optimised for the production of polymer-stabilised Au nanoparticles through variation of several operational parameters, such as polyvinyl alcohol (PVA) and $\mathrm{NaBH}_{4}$ concentration, solution flow rate and reactor geometry. Moreover, we report for the first time the production of Au@Pd core-shell nanoparticles using a continuous flow method. Finally, the 'as produced' monoand bi-metallic catalysts were tested in a nitroaromatic reduction reaction and cinnamaldehyde hydrogenation reaction in order to demonstrate their superior catalytic activity compared to their counterpart materials prepared by conventional sol-immobilisation batch methods. 


\section{RESULTS AND DISCUSSION}

\section{Millifluidic Method for the Synthesis of Mono- and Bi-metallic Nanoparticles}

Figure 1(a) shows a schematic diagram of the millifluidic reactors designed in this work for the synthesis of monometallic $\mathrm{Au}$ and bimetallic random alloy $\mathrm{AuPd}$ nanoparticles supported on $\mathrm{TiO}_{2}$. The approach was to adapt a well-established sol-immobilisation batch synthesis method ${ }^{58,59}$ into a process which operates continuously. Full details of experimental set-up and operational parameters are disclosed in the Experimental Details section and are only described in outline here for the purpose of providing some context. Using a two-channel peristaltic pump, an aqueous solution containing the $\mathrm{Au}$ metal precursor $\left(\mathrm{HAuCl}_{4}\right)$ and stabilising agent (PVA) was mixed with a second solution containing the reducing agent $\left(\mathrm{NaBH}_{4}\right)$ in a T-shape connector unit (red inset, Figure 1(a)). Different connector shapes were fabricated through 3D printing, having characteristic T-, Y- or I-shapes (as shown in Figure 2). The mixed solution was then passed through an $80 \mathrm{~cm}$ length of PFA tube (1.14 mm internal diameter) which acted as the standard millifluidic reactor, giving a residence time of $8 \mathrm{~s}$ for a typical flow rate of $6 \mathrm{~mL} \mathrm{~min}^{-1}$. In later experiments, this simple tubing was replaced with specially designed 3D printed millifluidic reactors having more complex geometries to enhance mixing (Figure 2). Formation of small bubbles was observed in the reactor due to the decomposition of $\mathrm{NaBH}_{4}$ in water; these bubbles, with their associated motion, can create liquid segments that act as independent microreactors, further enhancing the solution mixing. ${ }^{60}$ After passing through the millifluidic reactor, the colloids were examined on-stream by a UV-vis spectrometry system integrated into the apparatus. The formation of the characteristic ruby red coloured Au colloid commenced immediately on mixing at which indicated that the $\mathrm{Au}^{3+}$ precursor present in solution was completely reduced, as evidenced by the absence of the characteristic $\mathrm{AuCl}_{4}{ }^{-}$absorption band at $c a .310 \mathrm{~nm}$ in the $\mathrm{UV}$-vis spectrum acquired on-line 
(Supplementary Information, Figure S2(a), inset). After passing through the UV-vis spectrometer, the colloidal solution can either be collected for subsequent immobilisation off-line (setup 1), or it can pass through a final module stage of the apparatus for direct continuous immobilisation on $\mathrm{TiO}_{2}$ (setup 2). In setup 1 (the semi-continuous synthesis approach), the colloidal solution was manually added into a beaker pre-loaded with support material suspended in water. In setup 2 (the continuous synthesis approach), an additional peristaltic pump was incorporated into the apparatus in order to combine a continuous stream of titanium oxide support suspended in water with the metal colloid. In both cases, the resultant mixture was then filtered, washed and dried to obtain the final supported metal nanoparticle material.

The synthesis of Au@Pd core-shell nanoparticles was carried out in a modified version of setup 1 (see setup 3, Figure 1(b)). A second peristaltic pump was incorporated in order to add the second metal precursor $\left(\mathrm{PdCl}_{2}\right)$ and reducing agent solutions to the Au colloid stream. The three solutions were mixed using an ad-hoc 3D printed 4-way connection unit (orange inset, Figure 1(b)). No extra PVA was added to the Pd precursor solution.

\section{Optimisation of the Au Nanoparticle Synthesis Parameters}

Several key parameters for the synthesis of Au nanoparticles under flow conditions were firstly explored using the semi-continuous setup, such as $\mathrm{NaBH}_{4}$ and PVA concentration, and the method of solution mixing. A critical parameter in producing uniform metallic nanoparticles is the efficient mixing inside the reactor tubing. In the straight channels of typical millifluidic devices, mixing can be problematical due to laminar flow and lack of mechanical stirring. To overcome these problems, two parameters can be optimised, namely the flow rate of the solutions and the connector/reactor geometry. The total flow rate of the metal precursor/stabiliser and reductant 
solutions was varied between 1 and $24 \mathrm{~mL} \mathrm{~min}^{-1}$ (giving an overall corresponding variation in residence time between 48 and 2 s respectively), with each solution having the same flow rate. Reynolds numbers $(\mathrm{Re})$ were calculated for all the flow rates used and varied from 13 at $1 \mathrm{~mL}$ $\min ^{-1}$ up to 320 at $24 \mathrm{~mL} \min ^{-1}$, confirming the presence of a laminar flow environment (i.e., $\operatorname{Re}<$ 2,300). ${ }^{61}$ It has been reported that higher flow rates tend to increase the degree of mixing in the region of T-shape connectors due to the formation and intensification of a secondary flow in the form of a double vortex pair, analogous to Dean vortices characteristic of flow in curved pipes. ${ }^{62}$ This has the potential to cause a faster nucleation step that results in the production of smaller seed particles and narrower nanoparticle size distributions. ${ }^{63}$ This is consistent with our observations, where the mean nanoparticle size, determined from scanning transmission electron microscopy analysis decreased from $15.1 \mathrm{~nm}$ at $1 \mathrm{~mL} \mathrm{~min}^{-1}$ to $5.6 \mathrm{~nm}$ at $24 \mathrm{~mL} \mathrm{~min}{ }^{-1}$ (Table 1, Entries 1-6), with the relative standard deviation in Au nanoparticle diameter decreasing accordingly from \pm $6.2 \mathrm{~nm}$ to $\pm 1.3 \mathrm{~nm}$. Table 1 also shows dynamic light scattering (DLS) analysis of particle size in the colloidal solutions whose trends were in good agreement with the electron microscopy analysis. The intensity and shape of the Au surface plasmon resonance peak are also indicative of the nanoparticle size distribution. ${ }^{64}$ In particular, the smaller the mean Au nanoparticle size in the colloid, the broader the surface plasmon resonance peak and the more shifted it is towards shorter wavelengths, e.g. $505 \mathrm{~nm} .{ }^{65,66}$ Figure S2(a) shows the recorded plasmon resonance from in-line UV-vis analysis acquired at differing flow rates and demonstrates that the absorption peak is shifted from $510 \mathrm{~nm}$ at $1 \mathrm{~mL} \mathrm{~min}^{-1}$ to $504 \mathrm{~nm}$ at $24 \mathrm{~mL} \mathrm{~min}^{-1}$, indicating that smaller nanoparticles were being formed at higher flow rates.

The solution mixing can be tuned via changing the geometry of the connector unit and the millifluidic reactor using a stereo-lithographic 3D printer. It has been previously reported that the 
tubing material can affect the quality of the metal colloid produced ${ }^{67}$ In this work, we compared the default T-shape connector, with alternative Y-shape and I-shape connectors (Figure 2). The Yshape connection simply allows the two streams to merge with a lower contact angle compared to the T-shape connector, while the I-shape connector unit can be defined as a coaxial mixer where the two solutions make contact in the same flow direction, with the $\mathrm{Au}^{3+}$ solution forced into the $\mathrm{NaBH}_{4}$ solution for better mixing (Supplementary Information, Figure S1). Indeed, in our case, a noticeable change in the mean size of nanoparticles was noticed when different connectors were used (Table 1, entries 7-9). For instance, a catalyst produced with the standard I-shape connector gives a smaller mean particle size $(6.5 \pm 1.7 \mathrm{~nm})$ compared to a catalyst produced with a T-shape connection $(7.0 \pm 1.9 \mathrm{~nm})$. Specially shaped reactors, having helical or plait-like geometries (Figure 2) were also 3D printed and tested in conjunction with a T-shape connector (Table 1, entries 10-11). The helix design is an 8-turn helicoidal shaped reactor that takes advantage of its 3-dimensional curves to intensify the so-called Dean vortices and thus increase the degree of mixing. The plait-like reactor is a device where the two solutions split and recombine multiple times on a 2-dimensional plane along their pathway. The results show that amongst the tested geometries, the I-shape connection and the helical reactor produced the smallest and most uniform nanoparticles $(6.4 \pm 1.5 \mathrm{~nm}$ and $6.3 \pm 1.3 \mathrm{~nm}$ respectively), whereas the plait-like reactor and the Y-shape connection proved to be the least effective configurations $(7.4 \pm 2.2 \mathrm{~nm}$ and $7.5 \pm 2.5 \mathrm{~nm}$ respectively).

Finally, we observed that an optimum value of $\mathrm{NaBH}_{4}$ and PVA concentration was required in order to produce small and uniform Au nanoparticles; low amounts of $\mathrm{NaBH}_{4}$ were not enough to rapidly reduce all the metal precursor, while an excess of reducing agent caused a destabilising effect due to the excess of electrolytes in solution and PVA hydrolysis (Table 1, entries 12-15). ${ }^{68}$ 
Similarly, the absence of the stabilising agent, as expected, led to the production of large nanoparticles through particle agglomeration and coalescence (Table 1, entry 16). On the other hand, an excess of PVA did not significantly change the characteristics of the final Au colloid (Table 1, entry 18). For catalysis applications, however, it is desirable to use the lowest amount of stabilising agent possible since these ligands may block or decrease the accessibility of the metal active sites from the substrate, affect adsorption/desorption of substrates/products and thus decrease the overall activity.

\section{Continuous Production of Supported Au Nanoparticles}

Following our successful optimisation of the semi-continuous process, we further explored generating supported metal nanoparticles in a one-step 'continuous' process. An additional peristaltic pump was added into the apparatus in order to integrate a continuous stream of the $\mathrm{TiO}_{2}$ support suspended in water with that of the Au colloid (Figure 1(a), setup 2).

The $\mathrm{Au} / \mathrm{TiO}_{2}$ material as produced was then compared with the benchmark $\mathrm{Au} / \mathrm{TiO}_{2}$ catalyst prepared by the standard batch sol-immobilisation method (see Table S1). The continuous addition of support facilitated the production of very well-dispersed Au nanoparticles with a small mean particle size and narrow size distribution $(4.5 \pm 1.3 \mathrm{~nm})$ as determined by HAADF-STEM analysis (Figure 2). Comparison with the batch catalysts showed that the mean size of the nanoparticle decreased from $5.6 \mathrm{~nm}$ to $4.5 \mathrm{~nm}$, with the corresponding particle size distribution also slightly decreasing from 1.6 to $1.3 \mathrm{~nm}$ (Figure S3). It is clear that the rapid formation and immediate deposition in a continuous fashion of the Au colloid onto the $\mathrm{TiO}_{2}$ support is highly beneficial. This positive outcome is ascribed to two main effects; firstly, the absence of mechanical stirring, which is inherent to the batch synthesis method, minimises agglomeration phenomena: and secondly, the fast removal of the remaining $\mathrm{NaBH}_{4}$ in solution by immediate filtration of the 
catalyst, which can interfere with the interaction of the PVA ligand with the colloid thus reducing the stabilising effect of the polymer. The metal loading of the continuous catalyst, as measured by MP-AES, was comparable to that of the batch preparation (at $0.96 \mathrm{wt} \%$ and $0.94 \mathrm{wt} \%$ respectively), confirming that any metal deposition on the internal walls of the tubing was negligible under the optimised reaction conditions. Additional MP-AES analysis was carried out on the filtrate solution in order to confirm complete reduction of the metal and deposition of the nanoparticles onto the support: no residual $\mathrm{Au}$ species were detected in solution. Diffuse reflectance UV-vis spectroscopy was performed on the three catalysts and the results (Figure S4) are in accordance with both electron microscopy and absorption UV-vis analysis. The Au surface plasmon resonance of the continuous-prepared catalyst was very weak and broad compared to that of the batch derived material, and the maximum intensity occurred at shorter wavelengths (i.e., $536 \mathrm{~nm}$ for the continuous catalyst, as compared to $540 \mathrm{~nm}$ of the batch prepared materials). All the plasmon resonance features in Figure S4 were shifted towards longer wavelengths compared to those in the absorption UV-vis spectra derived from the colloidal samples (Figure S2) due to interaction between the $\mathrm{Au}$ nanoparticles and the $\mathrm{TiO}_{2}$ support. ${ }^{69}$ XPS analyses were also performed on the catalysts prepared by the batch and the continuous methods (Table S1 and Figure $\mathrm{S} 5(\mathrm{a}))$. The $\mathrm{Au}(4 \mathrm{f})$ spectra showed the presence of metallic Au in all cases, with the $\mathrm{Au} 4 \mathrm{f}_{7 / 2}$ binding energy values $(\mathrm{BE})$ being in the $83.6-83.7 \mathrm{eV}$ range in agreement with previous reports. ${ }^{70}$ No significant difference in $\mathrm{Au} 4 \mathrm{f}_{7 / 2} \mathrm{BE}$ was detected amongst the samples analysed.

\section{Continuous Production of Supported AuPd Random Alloy Nanoparticles}

The same experimental setup used for the continuous production of supported Au colloids was then used for the synthesis of random alloy AuPd nanoparticles supported on $\mathrm{TiO}_{2}$. The $\mathrm{Au}$ and Pd precursors were mixed together immediately prior to pumping into the apparatus, in order to 
have simultaneous reduction of the two metals by the $\mathrm{NaBH}_{4}$ and thus generate alloy nanoparticles. The catalyst produced was compared with a benchmark $\mathrm{AuPd} / \mathrm{TiO}_{2}$ catalyst made by a batch solimmobilisation process, and the results are reported in Table S1. From electron microscopy analysis (Figures 4(a, b) and S3(c, d)), the mean size and particle size distribution were similar at $2.1 \pm 0.7 \mathrm{~nm}$ for the batch derived materials and $2.0 \pm 0.7 \mathrm{~nm}$ for those made by the continuous process.

XPS analysis was also performed on both catalysts to monitor any electronic differences caused by the different synthesis methods (Figure S5). The Au (4f $\mathrm{f}_{7 / 2}$ ) peaks in both cases (see Figure S5(a)) were between $83.0-83.2 \mathrm{eV}$, which is lower than that of bulk gold (ca. $84.0 \mathrm{eV})$. This decrease in binding energy (BE) is due to particle size effects and to electronic interactions between $\mathrm{Au}$ and Pd, confirming the presence of small alloy nanoparticles. ${ }^{71}$ Since electron microscopy analysis confirmed the presence of a similar particle size distribution for the two catalysts (Figures 4(a, b) and S3(c, d)), the binding energy shift from $83.2 \mathrm{eV}$ to $83.0 \mathrm{eV}$ might be indicative of an increased interaction between the two metals (or a more homogeneous AuPd composition). In accordance with these results, a slight downshift was also observed in the metallic $\operatorname{Pd}\left(3 \mathrm{~d}_{5 / 2}\right)$ band (Figure S5(b)), from $335.0 \mathrm{eV}$ for pure Pd to $334.6-334.7 \mathrm{eV}$ for the alloy samples, with the batch catalyst having the smaller BE shift. ${ }^{72,73} \mathrm{No} \mathrm{Pd}^{2+}$ species were observed at $c a .337 .0$ $\mathrm{eV}$, confirming the metallic state of the alloy nanoparticles.

The composition of individual alloy nanoparticles was quantified by use of an aberration-corrected STEM equipped with an energy dispersive X-ray spectrometer (XEDS). Previous detailed studies have shown that the conventional batch sol-immobilisation synthesis protocol in which PVA is used as the stabilising agent always resulted in a systematic composition variation with increasing AuPd particle size. ${ }^{37}$ Larger AuPd particles (i.e., $>5 \mathrm{~nm}$ ) were Pd-rich, while the smaller particles 
(i.e., $\sim 2 \mathrm{~nm}$ ) were consistently Au-rich. In contrast, the AuPd particles produced by the continuous synthesis protocol developed in this work display a AuPd composition which is almost invariant with particle size (Figures $4(\mathrm{c}, \mathrm{d})$ ). The average measured Pd composition of $c a .35 \mathrm{wt} \%$, corresponds well to a Au-to-Pd molar ratio of 1:1, which is in excellent agreement with the nominal value. Moreover, although several studies have been reported regarding the continuous production of metal nanoparticles, ${ }^{47,48,74}$ to the best of our knowledge, this is the first time that both the synthesis and immobilisation steps of a bimetallic colloid have been performed entirely in a continuous flow system. This new approach provides a reproducible and scalable synthesis method which provides good control over alloy particle size and more importantly, a superior consistency in alloy composition with particle size as compared to comparable materials made by the batch protocol. This important difference in compositional homogeneity is most likely due to the very fast deposition of the freshly formed AuPd nanoparticles on the support in the continuous synthesis route which effectively "locks-in" their structure and composition after only a few seconds of ageing. In the batch process, where there is a very significant time delay before immobilisation of the colloid, the extended ageing time in solution provides an opportunity for the colloid particles to intimately interact with one another, resulting in the observed characteristic composition variation with particle size.

\section{Continuous Production of Au@Pd Core-Shell Nanoparticles}

The synthesis of core-shell Au@Pd nanoparticles was carried out using the set-up 3 presented in Figure 1(b). The selective reduction of the $\mathrm{PdCl}_{2}$ precursor on the surface of pre-formed $\mathrm{Au}$ nanoparticles was carried out by mixing the three feed streams in a four-way connection. The three solutions, containing $\mathrm{Au}$ nanoparticles, $\mathrm{Pd}$ precursor and $\mathrm{NaBH}_{4}$ respectively, were fed into the four-way connection in the order shown in the yellow-inset of Figure 1(b). 
STEM-HAADF imaging of this sample confirmed the presence of some Au@Pd core-shell particles in the 3-5 nm with mean diameter of $c a .4 \mathrm{~nm}$ (Figure 5). Although some segregated monometallic particles were detected as well, we believe this is the first time Au@Pd core-shell structures have been intentionally produced in a single-phase continuous flow reactor and represent a starting point for a further optimisation of this process. The additional presence of monometallic Au and Pd particles in this non-optimised process is not entirely unexpected, as the former arise from uncoated $\mathrm{Au}$ seed particles, whereas the latter result from secondary Pd nucleation events occurring away from the Au colloid seeds.

\section{Application of Materials as Catalysts}

The catalytic performance of the $\mathrm{Au} / \mathrm{TiO}_{2}$ and $\mathrm{AuPd} / \mathrm{TiO}_{2}$ materials prepared by both the batch and continuous methods were evaluated in the hydrogenation of various nitroarenes to aminoarenes, while the comparison between $\mathrm{AuPd} / \mathrm{TiO}_{2}$ and $\mathrm{Au} @ \mathrm{Pd} / \mathrm{TiO}_{2}$ catalysts prepared in continuous mode was evaluated in the cinnamaldehyde hydrogenation reaction.

Nitroarenes are generally highly toxic, mutagenic and in many cases carcinogens. ${ }^{75,76}$ They can often be found in industrial and agricultural waste water as by-products of pesticides, herbicides and synthetic dyes, and their presence, even in small concentrations, is of great concern from an environmental point of view. ${ }^{77}$ The hydrogenation of nitroaromatic compounds can generate aminoarenes, important chemicals widely used by the pharmaceutical industry as analgesics, antipyretics and chemotherapeutics, and in agriculture as fungicides and pesticides. They are also used by the chemical industry as intermediates in the synthesis of polymers (polyurethanes), dyes, pigments, photographic chemicals and corrosion inhibitors. ${ }^{78}$

The nitroarenes studied were 4-nitrophenol (4-NPH), 3-nitrophenol (3-NPH), 2-nitrophenol (2$\mathrm{NPH}$ ), nitrobenzene (NBZ), 4-nitroaniline (4-NAL), 4-nitrotoluene (4-NTL) and 4-nitrobenzyl 
alcohol (4-NBA). The reduction of 4-nitrophenol (4-NPH) with $\mathrm{NaBH}_{4}$, in particular, has been frequently used as a model reaction to investigate the catalytic activity of supported metal nanoparticles having controlled size and shape. ${ }^{79,80}$ In our work, UV-vis spectroscopy has been used to monitor the consumption of the nitroarenes in a cuvette. For a typical measurement, the decrease in intensity with time of the substrate peak (typically at $c a .350-400 \mathrm{~nm}$ ) was used to calculate the rate constant of the reaction (see Figure S6(a)). Since the $\mathrm{NaBH}_{4}$ was present in excess, it was assumed that the reaction rate depended only on the concentration of nitroarenes, allowing us to approximate the kinetic data with a first-order rate law (as has been previously reported) ${ }^{80}$ The reaction constant (k) was then determined based on the kinetic equations described in the experimental method section of the Supplementary Information and used to compare the activity of the different catalysts. The inactivity of the bare support was confirmed beforehand: no significant nitroarene conversion was noticeable after 10 minutes of reaction.

The catalysts prepared in a continuous fashion consistently showed higher activity compared to that of the corresponding batch produced material (Table 2). This increase in activity can be better quantified in terms of the percentage difference in reaction constant $(\Delta k)$ between the $k$ values obtained for the batch and continuous derived catalysts. For the various substrates studied, the $\Delta k$ value was in the $6-50 \%$ range in favour of the continuously derived catalyst materials, with the 4-NBA and NBZ substrates showing the lowest and highest measured activity increase respectively. In the case of the continuous derived $\mathrm{Au} / \mathrm{TiO}_{2}$ catalyst, the greater activity was attributed to the smaller mean Au nanoparticle size, whereas, in the case of the continuous $\mathrm{AuPd} / \mathrm{TiO}_{2}$ catalyst the more uniform alloy composition and absence of Au-rich and Pd-rich nanoparticles in the material is thought to be responsible for the improvement in performance. 
Cinnamaldehyde is one of the most significant fragrance aldehydes, with an estimated production of $1.5 \mathrm{kton} /$ year via base-catalysed condensation of benzaldehyde and acetaldehyde. ${ }^{81}$ The products of hydrogenation of the vinyl $(\mathrm{C}=\mathrm{C})$ and carbonyl $(\mathrm{C}=\mathrm{O})$ group, hydrocinnamaldehyde (HCAL) and cinnamyl alcohol $(\mathrm{COH})$ respectively, are largely used in the production of various fine chemicals for the pharmaceutical and perfumery industry. ${ }^{81,82}$ In a previous study we demonstrated the synergistic effect of alloying $\mathrm{Au}$ and $\mathrm{Pd}$, reporting a peak in activity for $\mathrm{Au}: \mathrm{Pd}$ compositions of $50: 50 .{ }^{33}$ On the other hand, the selectivity did not follow the same behaviour, and high concentrations of HCAL were obtained with Pd-rich nanoparticles. Thus, we speculated that $\mathrm{Au} @ \mathrm{Pd}$ core-shell particles could offer high selectivity due to a Pd-rich surface while maintaining high CAL conversions thanks to the electronic effect of the Au core.

The $\mathrm{Au} @ \mathrm{Pd} / \mathrm{TiO}_{2}$ catalyst synthesised with the experimental setup 3 was tested and compared with the random alloy AuPd catalysts prepared by both continuous and batch synthesis (Table 3 ). The continuous $\mathrm{AuPd} / \mathrm{TiO}_{2}$ catalyst showed higher selectivity towards $\mathrm{HCAL}$ compared to the batch catalyst after $1 \mathrm{~h}$ of reaction (55\% versus $40 \%$ respectively), despite having a similar activity (55\% versus $52 \%$ CAL conversion respectively). Small Pd nanoparticles are reported to be more selective towards the $\mathrm{C}=\mathrm{C}$ hydrogenation for this particular reaction. ${ }^{83}$ However, as already pointed out, with the batch technique small nanoparticles are generally Au-rich. Therefore, the better alloy composition achieved with the continuous setup assures a constant surface Pd content across the whole particle size range while maintaining a strong synergistic effect between the two metals. The core-shell catalyst, on the other hand, showed improvement in both activity and selectivity: $68 \%$ of CAL was converted after $1 \mathrm{~h}$ with $63 \%$ of the products being HCAL. The enhanced activity can be attributed to the strong electronic effect between the Au core and the Pd surface, while the high HCAL selectivity is due to the presence of a Pd-rich surface. 


\section{CONCLUSIONS}

A very simple, versatile and easy to construct millifluidic reactor system has been developed for the synthesis of metal nanoparticles with excellent size and composition control. Various experimental parameters of the system have been firstly optimised for the synthesis of monometallic Au nanoparticles. It has been demonstrated that efficient mixing, combined with optimised values of PVA-to-Au and $\mathrm{NaBH}_{4}$-to-Au ratios, are required for the synthesis of small nanoparticles with a narrow size distribution. In addition, we have shown that supported nanoparticles can be synthesised in a one-step continuous process in which a suspension of $\mathrm{TiO}_{2}$ support material is directly incorporated into the colloid stream, achieving rapid immobilisation of the particles which minimises their opportunity for growth and agglomeration. The simplicity, efficiency and better control of the newly developed process has been demonstrated by critical comparison to materials produced by the conventional batch sol-immobilisation process.

More importantly, supported bimetallic AuPd nanoparticles have been efficiently synthesised and supported entirely in a continuous fashion. Through the use of localised single particle STEMXEDs analysis we demonstrated the absence of the size-dependent composition variations typically observed in PVA-stabilised bimetallic colloids prepared by batch sol-immobilisation methods. In addition, the optimised setup has been adapted for the synthesis of Au@Pd core-shell nanoparticles showing for the first time that bimetallic Au@Pd core-shell nanoparticles can be synthesised and supported in a single-phase continuous reactor directly from reduction of the constituent metal precursors in solution. 
From an application standpoint, the $\mathrm{Au}$ and $\mathrm{AuPd}$ catalysts prepared in a continuous fashion always showed higher activity in the hydrogenation of nitroarenes to aminoarenes compared to those prepared in batch. This improvement in performance was attributed to the smaller particle size in the case of the $\mathrm{Au} / \mathrm{TiO}_{2}$ catalyst, while to a more uniform alloy composition and absence of Au-rich and Pd-rich nanoparticles in the case of the continuous $\mathrm{AuPd} / \mathrm{TiO}_{2}$ catalyst. Moreover, the core-shell catalyst showed better performance in the selective hydrogenation of cinnamaldehyde compared to both the batch and the continuous random-alloy catalysts. The latter activity enhancement was attributed to the strong synergistic effect between the Au-core and the Pd-surface layer, while the high hydrocinnamaldehyde selectivity was attributed to the presence of a Pd-rich surface.

This work represents a starting point for the efficient production of uniformly dispersed supported metal nanoparticles having very reproducible structural and compositional characteristics. It can also potentially be applied in the production of a much wider range of supported mono-metallic and bi-metallic nanoparticles with desirable functional properties. In addition, this technique should also be highly appealing for the industrial production of supported colloidal catalysts, especially due to the ease of scale-up and the relative low-cost and simplicity compared to other competing continuous flow technologies. 


\section{EXPERIMENTAL DETAILS}

\section{Materials}

Reactor construction - For the semi-continuous setup, a dual channel peristaltic pump (ColeParmer Masterflex C/S) was used in combination with Puri-Flex tubing (i.d. $=1.14 \mathrm{~mm}$ or 2.79 $\mathrm{mm}$ ), a quartz flow cell (Agilent, $10 \mathrm{~mm}$ path-length) and perfluoroalkoxy alkane (PFA) T-shape connections (Swagelok, i.d. $=3.17 \mathrm{~mm}$ ). The continuous setup and the core-shell setup simply added an additional peristaltic pump (Cole-Parmer Masterflex $\mathrm{C} / \mathrm{S}$ ) to the previous apparatus. A Formlabs Form 2 SLA 3D printer equipped with a standard clear photoreactive resin (mixture of methacrylic acid esters and photo-initiators) was used for the production of custom-made connections and reactors. The parts were designed using CAD software (Autodesk AutoCAD) and elaborated with the 3D printer software (PreForm) in order to add the necessary supports. After the printing step, the parts were washed for $10 \mathrm{~min}$ in 2-propanol in order to remove any residual liquid resin that remained inside the channels and then the printing supports were removed. Finally, all the parts underwent a post-curing process consisting of $16 \mathrm{~h}$ exposure to UV light $(365 \mathrm{~nm})$.

Catalyst synthesis - Hydrogen tetrachloroaurate $\left(\mathrm{HAuCl}_{4}, 99.999 \%\right)$, palladium chloride $\left(\mathrm{PdCl}_{2}\right.$, 99.999\%), poly(vinyl alcohol) (PVA, $\mathrm{M}_{\mathrm{w}}=9,000-10,000,80 \%$ hydrolysed), sodium borohydride $\left(\mathrm{NaBH}_{4}, 99.99 \%\right)$, titanium dioxide $\left(\mathrm{TiO}_{2}\right.$, Degussa $\left.\mathrm{P} 25\right)$ and sulphuric acid $\left(\mathrm{H}_{2} \mathrm{SO}_{4}, 95 \%\right)$ were purchased from Sigma-Aldrich and used for the synthesis of catalysts.

Catalytic testing - 4-nitrophenol (4-NPH, $99 \%$ ), 3-nitrophenol (3-NPH, $99 \%$ ), 2-nitrophenol (2NPH, 98 \%), nitrobenzene (NBZ, 99 \%), 4-nitroaniline (4-NAL, $99 \%$ ), 4-nitrotoluene (4-NTL, 99 $\%)$ and 4-nitrobenzyl alcohol (4-NBA, $99 \%$ ) were used in the nitroarene reduction reactions and purchased from Sigma-Aldrich. Cinnamaldehyde (Sigma-Aldrich, 99\%), cinnamyl alcohol (Alfa 
Aesar, 95\%), hydrocinnamaldehyde (Sigma-Aldrich, 98\%), hydrocinnamyl alcohol (SigmaAldrich, 98\%), phenylpropane (Sigma-Aldrich, 98\%) and toluene (Sigma-Aldrich, >99\%) were used in the cinnamaldehyde hydrogenation reaction.

\section{Catalyst Synthesis}

Preparation of monometallic Au and bimetallic AuPd catalysts by the semi-continuous (setup 1) and continuous (setup 2) methods (Figure 1(a))

The following procedure was applied for the preparation of $0.5 \mathrm{~g}$ of a $1 \mathrm{wt} \% \mathrm{TiO}_{2}$-supported $\mathrm{Au}$ or AuPd (with molar ratio $1: 1$ ) catalyst. $5 \mathrm{mg}$ of metal were added to $100 \mathrm{~mL}$ of deionised water from metal precursor solutions. In particular, when monometallic Au nanoparticles were being produced, $0.400 \mathrm{~mL}$ of a $12.5 \mathrm{mg}_{\mathrm{Au}} \mathrm{mL}^{-1}$ solution was used, whereas when bimetallic AuPd nanoparticles were being produced, $0.293 \mathrm{~mL}$ of a $6.0 \mathrm{mg}_{\mathrm{Pd}} \mathrm{mL}^{-1}$ solution containing $0.58 \mathrm{~mol} \mathrm{~L}^{-}$ ${ }^{1}$ of $\mathrm{HCl}$ and $0.260 \mathrm{~mL}$ of a $12.5 \mathrm{mg}_{\mathrm{Au}} \mathrm{mL}^{-1}$ solution was used. After 5 min under constant stirring, a $1 \mathrm{wt} \%$ solution of polyvinyl alcohol $(\mathrm{PVA})$ was added $(0.350 \mathrm{~mL}$, PVA : metal weight ratio $=$ 0.65). In another beaker, the appropriate amount of a freshly prepared $0.1 \mathrm{M}$ solution of $\mathrm{NaBH}_{4}$ was added to $100 \mathrm{~mL}$ of deionised water $\left(\mathrm{NaBH}_{4}:\right.$ metal molar ratio $\left.=5: 1\right)$. The two solutions were pumped together with the desired flow rate (typically $3 \mathrm{~mL} \mathrm{~min}^{-1}$ per solution, total flow rate $=6 \mathrm{~mL} \min ^{-1}$ ) through a peristaltic pump into either a commercial perfluoroalkoxy alkane (PVA) T-shape connection or into a 3D printed reactor (see Figure 2). The metal colloid prepared was pumped into Microbore Puri-Flex tubing (total reactor length $=80 \mathrm{~cm}$, internal diameter $1.14 \mathrm{~mm}$ ) connected to a UV-vis spectrometer flow-cell. At the end of the flow-cell, the colloid was either allowed to collect into a beaker containing $0.495 \mathrm{~g}$ of support stirred in $100 \mathrm{~mL}$ of slightly acidic deionised water ( 3 drops of $\mathrm{H}_{2} \mathrm{SO}_{4}(98 \%)$ to reach $\mathrm{pH} 1$ ) or merged into a stream of the same 
support suspension through a PFA T-shape connection. In either case, the resulting slurry was filtered with a Büchner funnel, washed with $1 \mathrm{~L}$ of deionised water and dried at room temperature for $48 \mathrm{~h}$. A sample of colloid ( $c a .1 \mathrm{~mL}$ ) was taken before immobilisation onto the support for DLS analysis.

Semi-continuous preparation of a supported Au@Pd core-shell morphology catalyst (setup 3, Figure 1(b))

The following procedure was applied for the preparation of $0.5 \mathrm{~g}$ of a $1 \mathrm{wt} \% \mathrm{TiO}_{2}$-supported $\mathrm{Au} @$ Pd (with molar ratio $1: 1$ ) catalyst. $3.2 \mathrm{mg}$ of Au were added to $100 \mathrm{~mL}$ of deionised water from a metal precursor solution $\left(0.260 \mathrm{~mL}\right.$ of a $12.5 \mathrm{mg}_{\mathrm{Au}} \mathrm{mL}^{-1}$ solution). After 5 min under constant stirring, a $1 \mathrm{wt} \%$ solution of polyvinyl alcohol (PVA) was added $(0.350 \mathrm{~mL}$, PVA : $\mathrm{Au}+\mathrm{Pd}$ metal weight ratio $=0.65)$. In another beaker, the appropriate amount of a freshly prepared $0.1 \mathrm{M}$ solution of $\mathrm{NaBH}_{4}$ was added to $100 \mathrm{~mL}$ of deionised water $\left(\mathrm{NaBH}_{4}:\right.$ Au molar ratio $=5$ : 1). The two solutions were pumped together with a combined flow rate of $6 \mathrm{~mL} \mathrm{~min}^{-1}(3 \mathrm{~mL} \mathrm{~min}-$ ${ }^{1}$ per solution) through a peristaltic pump in a PFA T-shape connection. The Au colloid prepared was pumped into microbore puri-flex tubing (total reactor length $=80 \mathrm{~cm}$ ) connected to a UV-vis flow-cell. In the meantime, a $100 \mathrm{~mL}$ aqueous solution containing $1.8 \mathrm{mg}$ of $\mathrm{Pd}(0.293 \mathrm{~mL}$ of a $6.0 \mathrm{mg}_{\mathrm{Pd}} \mathrm{mL}^{-1}$ solution containing $0.58 \mathrm{~mol} \mathrm{~L}^{-1}$ of $\mathrm{HCl}$ ) was prepared, along with another $100 \mathrm{~mL}$ of a freshly prepared $\mathrm{NaBH}_{4}$ solution $\left(\mathrm{NaBH}_{4}: \mathrm{Pd}\right.$ molar ratio $\left.=5: 1\right)$. The three solutions (the $\mathrm{Au}$ colloid coming from the UV-vis flow cell, the Pd precursor solution and the $\mathrm{NaBH}_{4}$ solution) were merged together through a 3D printed 4-way connection (Figure 1). The as-prepared $\mathrm{Au} @ \mathrm{Pd}$ colloid passed through a $80 \mathrm{~cm}$ long microbore puri-flex tubing and finally flowed into a beaker containing $0.495 \mathrm{~g}$ of support stirred in $100 \mathrm{~mL}$ of slightly acidic deionised water (3 drops of 
$\mathrm{H}_{2} \mathrm{SO}_{4}(98 \%)$ to reach $\mathrm{pH}$ 1). The final catalyst was filtered with a Büchner funnel, washed with $1 \mathrm{~L}$ of deionised water and dried at room temperature for $48 \mathrm{~h}$.

\section{Materials Characterisation}

The Au colloids were analysed by dynamic light scattering (DLS, Malvern Zetasizer Nano ZS, $\lambda$ $=633 \mathrm{~nm})$ to determine the hydrodynamic diameter of the metal nanoparticles in a liquid environment. A UV-vis spectrometer (Agilent Cary 60) was used to determine the presence, position and intensity of the surface plasmon resonance peak of Au. The stream of Au colloid was analysed within the semi-continuous and continuous flow setups shown in Figure 1 by use of an in-situ quartz flow-through cell (Agilent, $10 \mathrm{~mm}$ path-length). The same UV-vis apparatus was used for monitoring the nitroarene (NAR) reduction reaction in the 200-500 $\mathrm{nm}$ range by using in this case a standard UV-vis quartz cuvette, while diffuse reflectance measurements were performed on an Agilent Cary 4000 instrument equipped with a praying mantis sample holder. The spectra were recorded over the $200-800 \mathrm{~nm}$ range.

X-ray photoelectron spectroscopy (XPS) measurements were performed on a Thermo Scientific $\mathrm{K}-\alpha^{+}$spectrometer. Samples were analysed using a monochromatic Al X-ray source operating at $72 \mathrm{~W}(6 \mathrm{~mA} \times 12 \mathrm{kV})$, with the signal averaged over an oval-shaped area of approximately 600 $\mu \mathrm{m} \times 400 \mu \mathrm{m}$. Data was recorded at pass energies of $150 \mathrm{eV}$ for survey scans and $40 \mathrm{eV}$ for high resolution scans with a $1 \mathrm{eV}$ and $0.1 \mathrm{eV}$ step size respectively. Charge neutralisation of the sample was achieved using a combination of both low energy electrons and argon ions (less than $1 \mathrm{eV}$ ) which gave a C(1s) binding energy of $284.8 \mathrm{eV}$. All data were analysed using CasaXPS (v2.3.17 PR1.1) using Scofield sensitivity factors and an energy exponent of -0.6. 
Scanning electron microscopy (SEM) experiments were carried out in a Tescan MAIA-3 FEGSEM operating at $30 \mathrm{kV}$. The instrument was equipped with a high angle dark-field retractable STEM detector allowing composition sensitive images to be taken in 'STEM-in-the-SEM' mode from $\mathrm{Au} / \mathrm{TiO}_{2}$ samples dry dispersed on a holey carbon TEM grid mounted on a special sample holder. Particle size histograms were constructed based on analysis of more than 400 nanoparticles measured using ImageJ software.

TEM experiments were carried out on a JEOL JEM-2100 electron microscope operating at a 200 $\mathrm{kV}$ accelerating voltage. The samples were first dispersed in ethanol and sonicated for 5 mins and then a drop was placed onto a 300-mesh carbon-coated copper grid. As per STEM-in-the-STEM analysis, particles size histograms were constructed considering at least 400 nanoparticles measured with ImageJ software.

Samples for examination by scanning transmission electron microscopy (STEM) were prepared by dry dispersing the catalyst powder onto a holey carbon film supported by a 300-mesh copper TEM grid. Bright field (BF) and high angle annular dark field (HAADF) STEM images were taken using an aberration corrected JEM ARM-200CF microscope operating at 200kV. This instrument was also equipped with a JEOL Centurio silicon drift detector for X-ray energy dispersive spectroscopy (XEDS). Characteristic X ray signals were collected from individual particles, and the composition of randomly selected particles were evaluated by analysing the intensity ratio of the Au M series versus the Pd L series X-ray peaks using The Cliff-Lorimer method, ${ }^{84}$ with a kfactor obtained from analysing a sputtered standard $60 \mathrm{wt} \% \mathrm{Au}-40 \mathrm{wt} \% \mathrm{Pd}$ thin film. The effects of atomic number, absorption and fluorescence are ignored as sizes of nanoparticles are small. Particle size distribution histograms were generated by analysis of more than 100 particles in representative HAADF electron micrographs using ImageJ. 
The metal loading of the catalysts was verified using an Agilent 4100 MP-AES system. In a typical experiment, $50 \mathrm{mg}$ of sample were digested in $4 \mathrm{~mL}$ of aqua regia, diluted to $50 \mathrm{~mL}$ and then left to digest for $16 \mathrm{~h}$. The solution was then filtered to remove the undissolved support, and the concentration was evaluated against a calibration solution freshly prepared before the analysis.

\section{Nitroarene (NAR) Reduction Reaction}

NAR reduction reactions were carried out in a quartz cuvette and monitored by UV-vis spectroscopy. The appropriate amount of catalyst $\left(1.2 \times 10^{-7}\right.$ mol of metal: $2.4 \mathrm{mg}$ of $\mathrm{Au} / \mathrm{TiO}_{2}$ or $1.9 \mathrm{mg}$ of $\mathrm{AuPd} / \mathrm{TiO}_{2}$ ) was placed inside the cuvette with $3 \times 10^{-7} \mathrm{~mol}$ of NAR. UV-vis analysis was then started just before addition of $3 \times 10^{-5}$ mol of $\mathrm{NaBH}_{4}$. The analysis consisted of a series of consecutive scans over the $200-500 \mathrm{~nm}$ range taken every $1.5 \mathrm{~s}$.

Since the $\mathrm{NaBH}_{4}$ was present in large excess, it was assumed that the reaction rate was dependant only on the concentration of NAR present, thus allowing us to approximate the kinetic data with a first-order rate law as previously has been reported for the reduction of 4-NPH. ${ }^{80}$ This approximation was subsequently confirmed to be valid by the linear correlation found between the substrate consumption expressed in terms of $-\ln \left(\mathrm{C}_{t} / \mathrm{C}_{0}\right)$ (where $\mathrm{C}_{\mathrm{t}}$ and $\mathrm{C}_{0}$ are the concentration at time $\mathrm{t}$ and at the start of the reaction respectively) and the reaction time (Supplementary Information, Figure S6B), which allowed the determination of the reaction rate constant $k$.

The kinetic equation for the NAR reduction reaction can be represented as follows:

$$
r=-\frac{d C_{t}}{d t}=k C_{t}
$$

where $k$ is the reaction rate constant, and its numerical value is the gradient of the linear correlation. 


\section{Cinnamaldehyde Hydrogenation Reaction}

Cinnamaldehyde hydrogenation reactions were carried out in a Radleys Carousel reactor using 3 parallel $50 \mathrm{~mL}$ glass reactors. $50 \mathrm{mg}$ of catalyst (substrate/metal molar ratio $1200: 1$ ) were added to the flask with $4 \mathrm{mmol}$ of substrate (cinnamaldehyde, CAL), $5 \mathrm{~mL}$ of solvent (toluene) and a magnetic bar for stirring. The reactors were purged with $\mathrm{H}_{2}$ three times, loaded with 1 bar $\mathrm{H}_{2}$ and sealed, maintaining them connected to the gas line to replenish the consumed $\mathrm{H}_{2}$ gas. The reactors were then loaded into a pre-heated heating block kept at the desired constant temperature $\left(100{ }^{\circ} \mathrm{C}\right)$. The stirring speed was set to $1000 \mathrm{rpm}$ in order to avoid mass transfer limitations and the reaction commenced. After $1 \mathrm{~h}$ the reactors were disconnected from the gas line and cooled down in an ice bath until they reached room temperature. The reaction mixture was centrifuged and an aliquot of the clear supernatant $(0.5 \mathrm{~mL})$ was mixed with an external standard solution $(0.5 \mathrm{~mL}$ of a $0.7 \mathrm{M}$ solution of o-xylene in toluene) for GC measurement. The analysis and quantification of the substrate and products was carried out by gas chromatography using a GC-FID (Agilent 7820A equipped with an Agilent HP- 5, $30 \mathrm{~m} \times 320 \mu \mathrm{m} \times 0.25 \mu \mathrm{m}$ column).

\section{CONFLICTS OF INTEREST}

The authors declare no conflict of interest.

\section{ELECTRONIC SUPPLEMENTARY INFORMATION AVAILABLE}

Additional schemes, tables, UV-vis spectra, TEM/STEM images and XPS spectra are provided in the Electronic Supplementary Information. 


\section{ACKNOWLEDGEMENTS}

We would like to thank MaxNet Energy for financial support and the Cardiff Electron Microscopy unit for use of facilities. CJK gratefully acknowledges funding from the National Science Foundation Major Research Instrumentation program (GR\# MRI/DMR1040229). SMA thanks the Saudi Arabian government for his PhD scholarship.

\section{REFERENCES}

1 S. Duraiswamy and S. A. Khan, Small, 2009, 5, 2828-2834.

2 A. Jimenez-Ruiz, P. Perez-Tejeda, E. Grueso, P. M. Castillo and R. Prado-Gotor, Chem. A Eur. J., 2015, 21, 9596-9609.

3 A. Hatzor and P. S. Weiss, Science, 2001, 291, 1019-1020.

4 C. Weng, C. Huang, C. Yeh, H. Lei and G. Lee, J. Micromechanics Microengineering, $2008,18,1-8$.

5 Y. Song, H. Modrow, L. L. Henry, C. K. Saw, E. E. Doomes, V. Palshin, J. Hormes and C. S. S. R. Kumar, Chem. Mater., 2006, 18, 2817-2827.

6 D. M. Alonso, S. G. Wettstein and J. A. Dumesic, Chem. Soc. Rev., 2012, 41, 8075-8098.

7 T. Chen and V. O. Rodionov, ACS Catal., 2016, 6, 4025-4033.

8 A. Alshammari, V. Kalevaru and A. Martin, Catalysts, 2016, 6, 1-24.

9 X. Yuan, X. Dou, K. Zheng and J. Xie, Part. Part. Syst. Charact., 2015, 32, 613-629.

10 P. Liu and J. K. Norskov, Phys. Chem. Chem. Phys., 2001, 3, 3814-3818.

11 R. Burch, Acc. Chem. Res., 1982, 15, 24-31.

12 M. Chen, D. Kumar, C.-W. Yi and D. W. Goodman, Science, 2005, 310, 291-293.

13 F. Liu, D. Wechsler and P. Zhang, Chem. Phys. Lett., 2008, 461, 254-259.

14 O. Metin, X. Sun and S. Sun, Nanoscale, 2013, 5, 910-912.

15 G. J. Hutchings, Chem. Commun., 2008, 1148-1164. 
G. J. Hutchings and C. J. Kiely, Acc. Chem. Res., 2013, 46, 1759-1772.

17 N. Dimitratos, J. A. Lopez-Sanchez, J. M. Anthonykutty, G. Brett, A. F. Carley, R. C. Tiruvalam, A. A. Herzing, C. J. Kiely, D. W. Knight and G. J. Hutchings, Phys. Chem. Chem. Phys., 2009, 11, 4952-4961.

18 P. Miedziak, M. Sankar, N. Dimitratos, J. A. Lopez-Sanchez, A. F. Carley, D. W. Knight, S. H. Taylor, C. J. Kiely and G. J. Hutchings, Catal. Today, 2011, 164, 315-319.

19 L. Kesavan, R. Tiruvalam, M. H. A. Rahim, M. I. bin Saiman, D. I. Enache, R. L. Jenkins, N. Dimitratos, J. A. Lopez-Sanchez, S. H. Taylor, D. W. Knight, C. J. Kiely and G. J. Hutchings, Science, 2011, 331, 195-199.

20 W. Luo, M. Sankar, A. M. Beale, Q. He, C. J. Kiely, P. C. A. Bruijnincx and B. M. Weckhuysen, Nat. Commun., 2015, 6, 1-10.

21 S. Nishimura, N. Ikeda and K. Ebitani, Catal. Today, 2014, 232, 89-98.

22 C. Jiaying, M. Hong, Z. Junjie, S. Qi, D. Zhongtian, H. Yizheng and X. Jie, Chem. - A Eur. J., 2013, 19, 14215-14223.

23 J. K. Edwards, A. F. Carley, A. A. Herzing, C. J. Kiely and G. J. Hutchings, Faraday Discuss., 2008, 138, 225-239.

24 J. K. Edwards and G. J. Hutchings, Angew. Chemie Int. Ed., 2008, 47, 9192-9198.

25 A. A. Ismail, A. Hakki and D. W. Bahnemann, J. Mol. Catal. A Chem., 2012, 358, 145151.

26 S. Panigrahi, S. Basu, S. Praharaj, S. Pande, S. Jana, A. Pal, S. Ghosh and T. Pal, J. Phys. Chem. C, 2009, 111, 4596-4605.

27 P. Suchomel, L. Kvitek, R. Prucek, A. Panacek, A. Halder, S. Vajda and R. Zboril, Sci. Rep., 2018, 8, 1-11.

28 N. Dimitratos, J. A. Lopez-Sanchez, D. Lennon, F. Porta, L. Prati and A. Villa, Catal. Letters, 2006, 108, 147-153.

29 D. Wang, A. Villa, F. Porta, L. Prati and D. Su, J. Phys. Chem. C, 2008, 112, 8617-8622.

30 D. I. Enache, D. Barker, J. K. Edwards, S. H. Taylor, D. W. Knight, A. F. Carley and G. J. Hutchings, Catal. Today, 2007, 122, 407-411.

31 L. Ouyang, G. J. Da, P. F. Tian, T. Y. Chen, G. Da Liang, J. Xu and Y. F. Han, J. Catal., 2014, 311, 129-136.

32 A. M. Venezia, L. F. Liotta, G. Pantaleo, V. La Parola, G. Deganello, A. Beck, Z. Koppány, K. Frey, D. Horváth and L. Guczi, Appl. Catal. A Gen., 2003, 251, 359-368. 
33 S. Cattaneo, S. J. Freakley, D. J. Morgan, M. Sankar, N. Dimitratos and G. J. Hutchings, Catal. Sci. Technol., 2018, 8, 1677-1685.

34 T. A. G. Silva, E. Teixeira-Neto, N. López and L. M. Rossi, Sci. Rep., 2014, 4, 5766.

35 J. A. Lopez-Sanchez, N. Dimitratos, P. Miedziak, E. Ntainjua, J. K. Edwards, D. Morgan, A. F. Carley, R. Tiruvalam, C. J. Kiely and G. J. Hutchings, Phys. Chem. Chem. Phys., 2008, 10, 1921-1930.

36 L. Gomez, V. Sebastian, S. Irusta, A. Ibarra, M. Arruebo and J. Santamaria, Lab Chip, 2014, 14, 325-332.

37 J. Pritchard, L. Kesavan, M. Piccinini, Q. He, R. Tiruvalam, N. Dimitratos, J. A. LopezSanchez, A. F. Carley, J. K. Edwards, C. J. Kiely and G. J. Hutchings, Langmuir, 2010, 26, $16568-16577$.

38 R. Schenk, V. Hessel, N. Jongen, V. Buscaglia, S. Guillement-Fritsch and A. G. Jones, Encycl. Nanosci. Nanotechnol., 2004, 7, 287-296.

39 J. DeMello and A. DeMello, Lab Chip, 2004, 4, 11N-15N.

40 A. Villa, D. Wang, D. S. Su and L. Prati, Catal. Sci. Technol., 2015, 5, 55-68.

41 S. Gómez-de Pedro, M. Puyol and J. Alonso-Chamarro, Nanotechnology, 2010, 21, 415603.

42 A. M. Karim, N. Al Hasan, S. Ivanov, S. Siefert, R. T. Kelly, N. G. Hallfors, A. Benavidez, L. Kovarik, A. Jenkins, R. E. Winans and A. K. Datye, J. Phys. Chem. C, 2015, 119, 1325713267.

43 S. E. Lohse, J. R. Eller, S. T. Sivapalan, M. R. Plews and C. J. Murphy, ACS Nano, 2013, 4135-4150.

44 K. J. Wu, G. M. De Varine Bohan and L. Torrente-Murciano, React. Chem. Eng., 2017, 2, 116-128.

45 K.-J. Wu, Y. Gao and L. Torrente-Murciano, Faraday Discuss., 2018, 208, 427-441.

46 H. Huang, H. du Toit, M. O. Besenhard, S. Ben-Jaber, P. Dobson, I. Parkin and A. Gavriilidis, Chem. Eng. Sci., 2018, 189, 422-430.

47 N. Hao, Y. Nie and J. X. J. Zhang, Int. Mater. Rev., 2018, 63, 1-27.

48 M. Rahman and E. Rebrov, Processes, 2014, 2, 466-493.

49 J. Wagner and J. M. Köhler, Nano Lett., 2005, 7, 1-7.

50 D. Shalom, R. C. R. Wootton, R. F. Winkle, B. F. Cottam, R. Vilar, A. J. DeMello and C. P. Wilde, Mater. Lett., 2007, 61, 1146-1150. 
H. Tsunoyama, N. Ichikuni and T. Tsukuda, Langmuir, 2008, 24, 11327-11330.

52 M. Luty-Błocho, K. Fitzner, V. Hessel, P. Löb, M. Maskos, D. Metzke, K. Pacławski and M. Wojnicki, Chem. Eng. J., 2011, 171, 279-290.

53 Y. Li, A. Sanampudi, V. Raji Reddy, S. Biswas, K. Nandakumar, D. Yemane, J. Goettert and C. S. S. R. Kumar, Chem. Phys. Chem., 2012, 13, 177-182.

54 K. S. Krishna, C. V Navin, S. Biswas, V. Singh, K. Ham, G. L. Bovenkamp, C. S. Theegala, T. Miller, J. J. Spivey and C. S. S. R. Kumar, J. Am. Chem. Soc., 2013, 135, 5450-5456.

55 M. K. Bayazit, J. Yue, E. Cao, A. Gavriilidis and J. Tang, ACS Sustain. Chem. Eng., 2016, 4, 6435-6442.

56 N. Hayashi, Y. Sakai, H. Tsunoyama and A. Nakajima, Langmuir, 2014, 30, 10539-10547.

57 G. Tofighi, A. Gaur, D. E. Doronkin, H. Lichtenberg, W. Wang, D. Wang, G. Rinke, A. Ewinger, R. Dittmeyer and J. D. Grunwaldt, J. Phys. Chem. C, 2018, 122, 1721-1731.

58 L. Prati and G. Martra, Gold Bull., 1999, 32, 96-101.

59 L. Prati and A. Villa, Catalysts, 2012, 2, 24-37.

60 A. Günther, S. a Khan, M. Thalmann, F. Trachsel and K. F. Jensen, Lab Chip, 2004, 4, 278286.

61 K. S. Elvira, X. Casadevall i Solvas, R. C. R. Wootton and A. J. de Mello, Nat. Chem., 2013, 5, 905-915.

62 D. Bothe, C. Stemich and H.-J. Warnecke, Chem. Eng. Sci., 2006, 61, 2950-2958.

63 J. Polte, Cryst. Eng. Comm., 2015, 17, 6809-6830.

64 G. L. Nealon, B. Donnio, R. Greget, J.-P. Kappler, E. Terazzi and J.-L. Gallani, Nanoscale, 2012, 4, 5244-5258.

65 M. Daniel and D. Astruc, Chem. Rev., 2004, 104, 293-346.

66 X. Zhang, Y. L. Chen, R. S. Liu and D. P. Tsai, Reports Prog. Phys., 2013, 76, 046401.

67 J. Boleininger, A. Kurz, V. Reuss and C. Sönnichsen, Phys. Chem. Chem. Phys., 2006, 8, 3824-3827.

68 B. Corain, G. Schmid and N. Toshima, Metal Nanoclusters in Catalysis and Materials Science: The Issue of Size Control, 2008.

69 A. Villa, N. Dimitratos, C. E. Chan-Thaw, C. Hammond, G. M. Veith, D. Wang, M. Manzoli, L. Prati and G. J. Hutchings, Chem. Soc. Rev., 2016, 45, 4953-4994. 
70 N. Dimitratos, J. A. Lopez-Sanchez, D. Morgan, A. F. Carley, R. Tiruvalam, C. J. Kiely, D. Bethell and G. J. Hutchings, Phys. Chem. Chem. Phys., 2009, 11, 5142-5153.

71 Y. Lee and Y. Jeon, J. Korean Phys. Soc., 2000, 37, 451-455.

72 W. F. Egelhoff, Surf. Sci. Rep., 1987, 6, 253-415.

73 Z. Li, F. Gao, Y. Wang, F. Calaza, L. Burkholder and W. T. Tysoe, Surf. Sci., 2007, 601, 1898-1908.

74 S. Marre and K. F. Jensen, Chem. Soc. Rev., 2010, 39, 1183-1202.

75 R. S. Padda, C. Wang, J. B. Hughes, R. Kutty and G. N. Bennet, Environ. Toxicol. Chem., 2009, 22, 2293-2297.

76 V. Purohit and A. K. Basu, Chem. Res. Toxicol., 2000, 13, 673-692.

77 United States Environmental Protection Agency, Priority Pollutant List, 2014.

78 P. F. Vogt and J. J. Gerulis, Amines, Aromatic in Ullmann's Encycl. Ind. Chem., 2005, 121.

79 P. Zhao, X. Feng, D. Huang, G. Yang and D. Astruc, Coord. Chem. Rev., 2015, 287, 114136.

80 T. Aditya, A. Pal and T. Pal, Chem. Commun., 2015, 51, 9410-9431.

81 C. Kohlpaintner, M. Schulte, J. Falbe, P. Lappe and J. Weber, Aldehydes, Aliphatic and Araliphatic in Ullmann's Encycl. Ind. Chem., 2005, 1-39.

82 K. Konno, H. Sakagami, Y. Kawazoe and N. Yamamoto, US 5632980 A, 1997.

83 F. Jiang, J. Cai, B. Liu, Y. Xu and X. Liu, RSC Adv., 2016, 6, 75541-75551.

84 G. Cliff and G. W. Lorimer, J. Microsc., 2018, 103, 203-207. 
Figure 1 -a) Schematic representation of the millifluidic reactor system in semi-continuous (Setup 1) and continuous mode (Setup 2). The inset red box shows the PFA T-shape connection. b) Schematic representation of the millifluidic reactor system for the synthesis of $\mathrm{Au} @ \mathrm{Pd}$ core-shell nanoparticles (Setup 3). The inset orange box shows the 3D printed 4-way connection.

a) Peristaltic pump

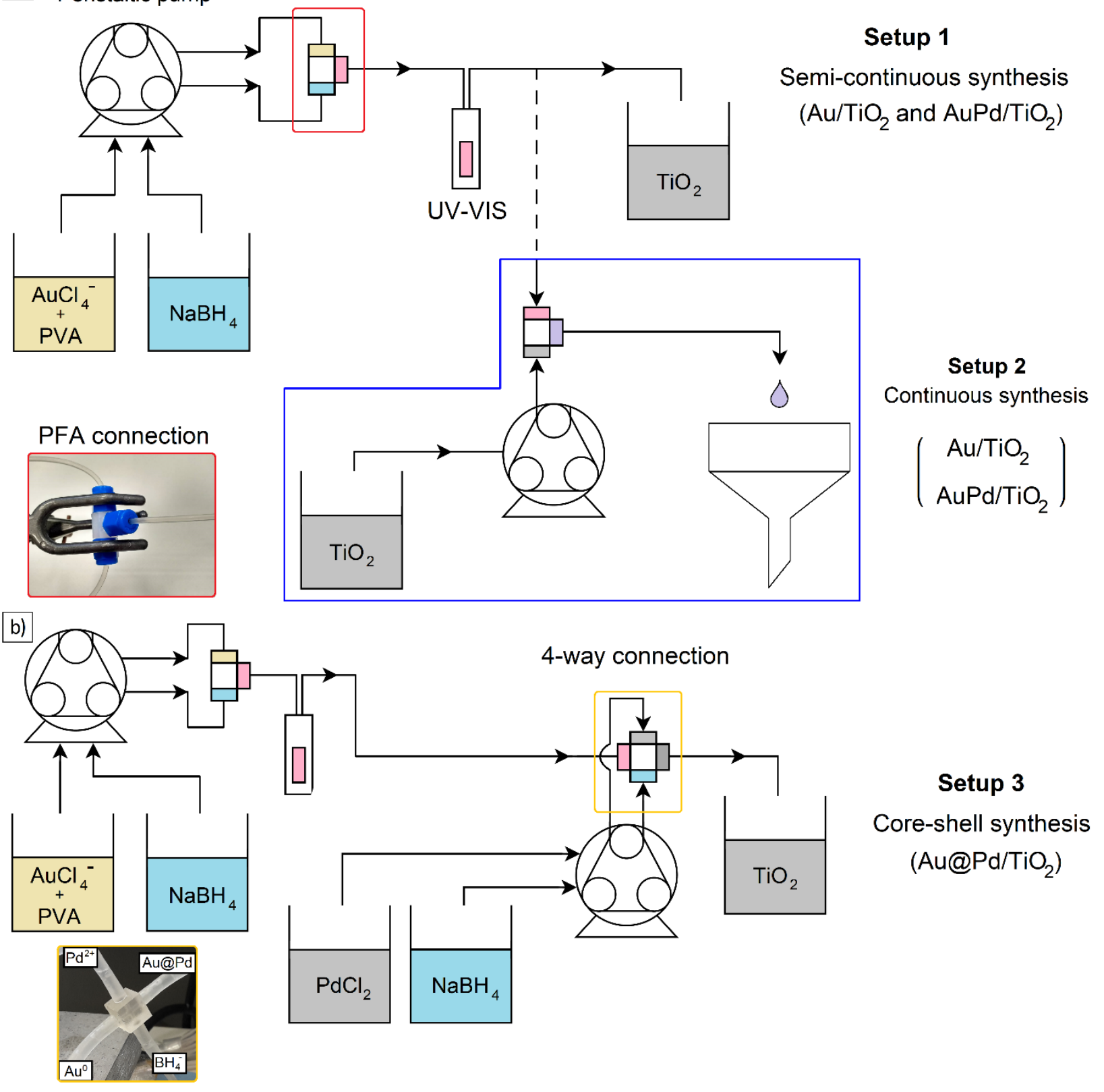


Figure 2 - Schematic diagram of the different 3D printed connectors (T-, Y- and I-type) and reactor geometries (helical and plait-like) tested in this work.

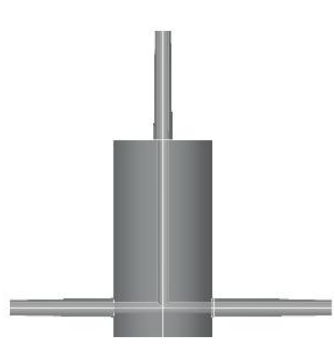

T-shape

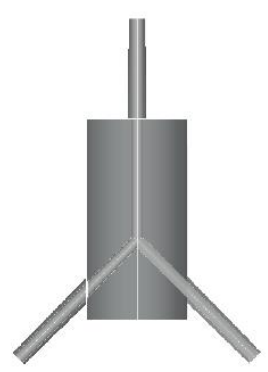

Y-shape

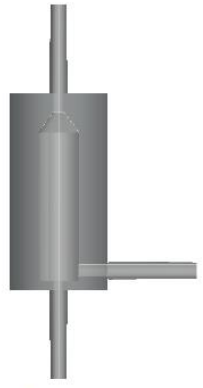

I-shape
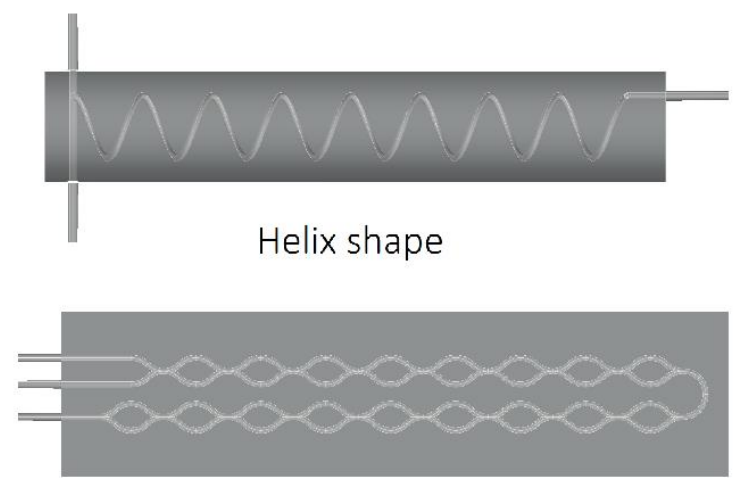

Plait-like shape 
Figure 3 - Representative a) STEM-HAADF image and b) particle size distribution of the $\mathrm{Au} / \mathrm{TiO}_{2}$ catalyst prepared by the continuous method. Reaction conditions: $8 \mathrm{~mL} \mathrm{~min}^{-1}$ flow rate, $80 \mathrm{~cm}$ reactor tube length with a standard PFA T-shape connection, PVA : Au weight ratio $=0.65$ $: 1$ and $\mathrm{NaBH}_{4}:$ Au molar ratio $=5: 1$.
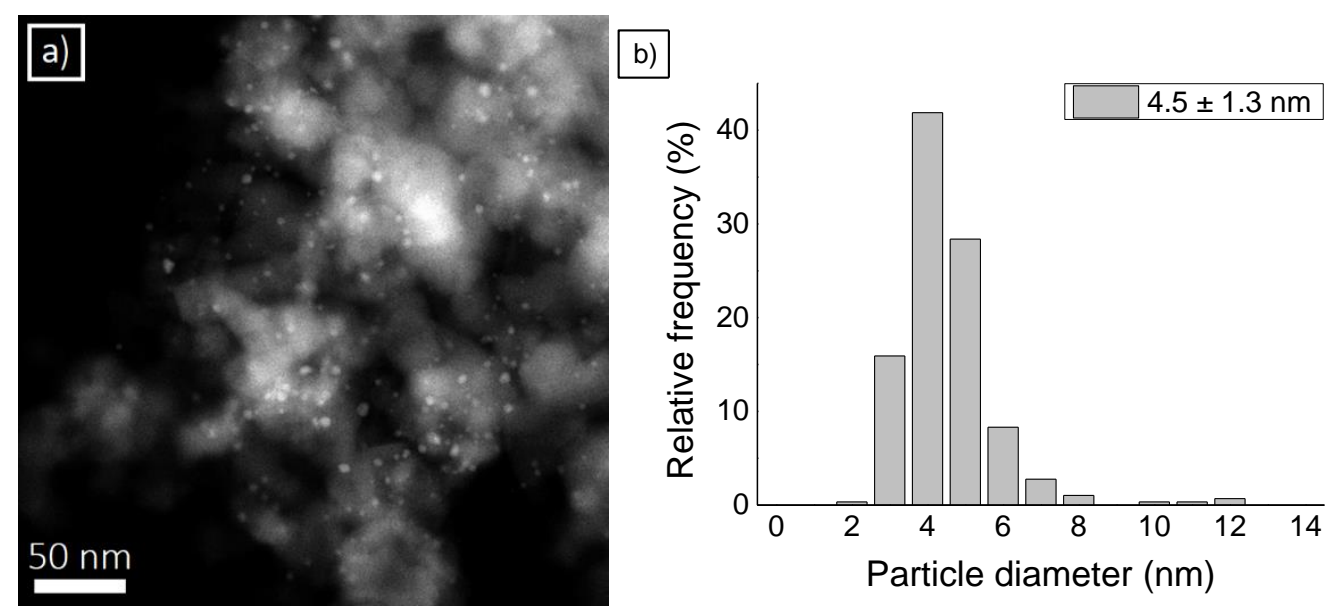
Figure 4 - Representative a) STEM-HAADF image and b) particle size distribution of the random alloy $\mathrm{AuPd} / \mathrm{TiO}_{2}$ catalyst prepared by the continuous method. Reaction conditions: $8 \mathrm{~mL} \mathrm{~min}^{-1}$ flow rate, $80 \mathrm{~cm}$ reactor length with a standard PFA T-shape connection, PVA : (Au+Pd) weight ratio $+1.2: 1$ and $\mathrm{NaBH}_{4}:(\mathrm{Au}+\mathrm{Pd})$ molar ratio $+5: 1$. c) Single particle XEDS analysis of the $\mathrm{AuPd} / \mathrm{TiO}_{2}$ catalyst prepared via the continuous method and d) composition versus size variation comparison between the $\mathrm{AuPd} / \mathrm{TiO}_{2}$ catalysts prepared by the conventional batch method and continuous method.
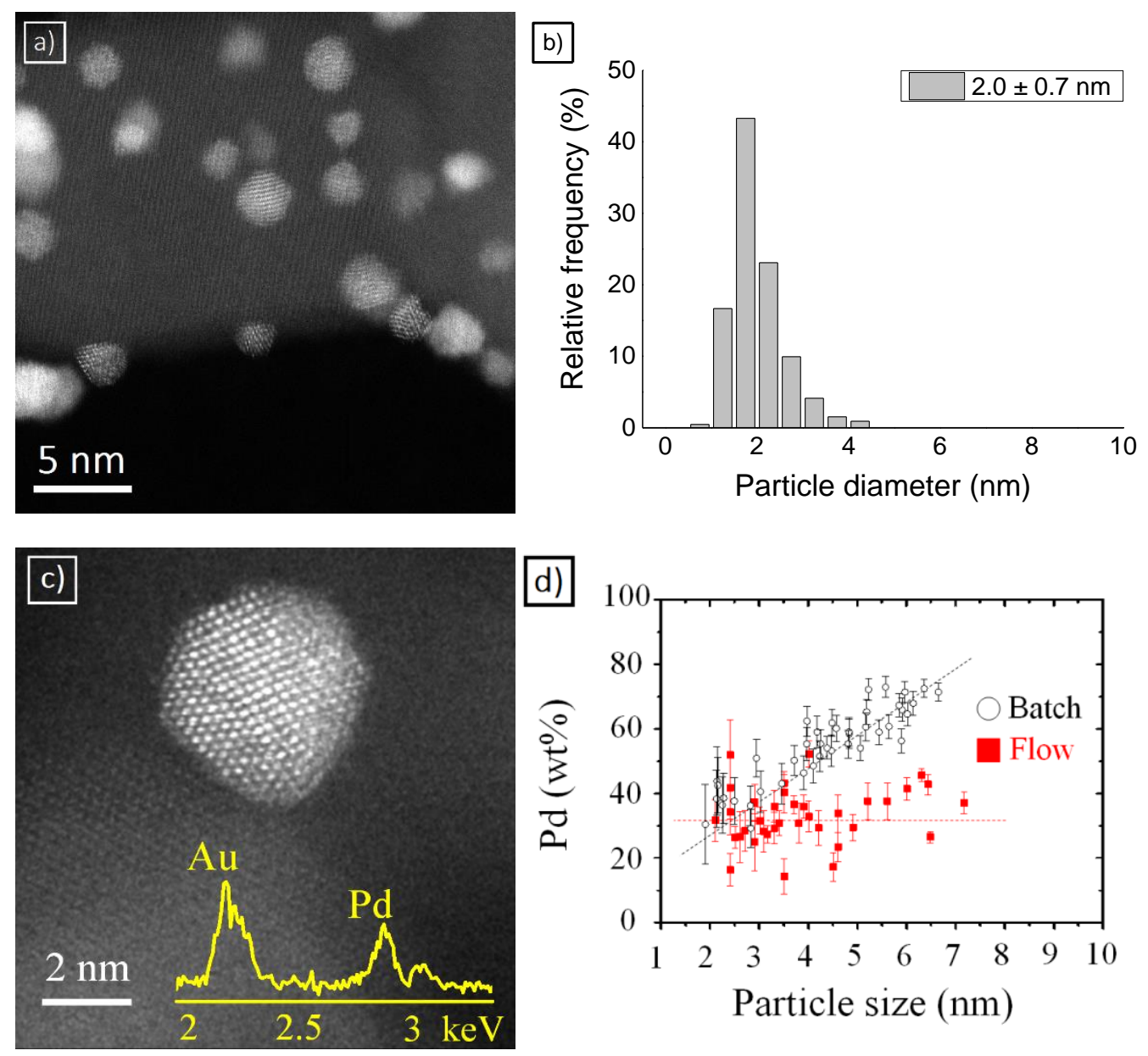
Figure 5 - Representative STEM-HAADF image of the $\mathrm{Au} @ \mathrm{Pd} / \mathrm{TiO}_{2}$ catalyst, showing the formation of some Au-core Pd-shell nanoparticles.

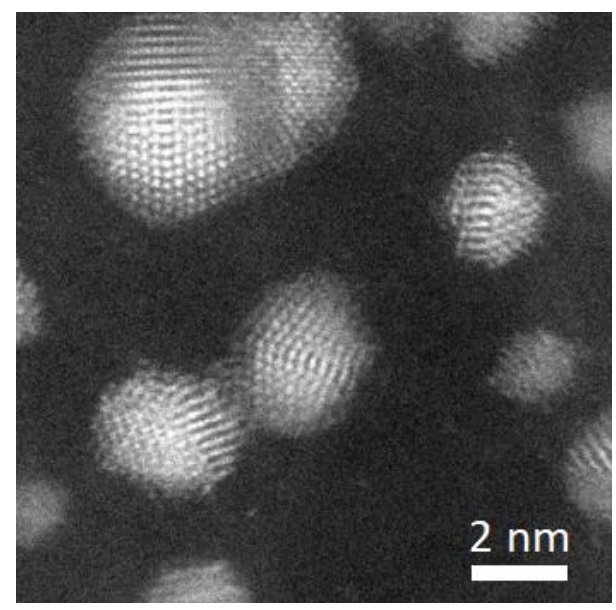


Table 1 - DLS and DF-STEM particle size measurements and metal loadings calculated for the $\mathrm{Au}$-colloid catalysts produced during the optimisation of the semi-continuous experimental setup.

\begin{tabular}{|c|c|c|c|c|c|c|}
\hline \multirow[b]{2}{*}{ Entry } & \multirow{2}{*}{$\begin{array}{l}\text { Flow rate } \\
\left(\mathrm{mL} \mathrm{min}^{-1}\right)\end{array}$} & \multirow{2}{*}{$\begin{array}{l}\text { PVA : Au } \\
\quad(\mathbf{g}: \mathbf{g})\end{array}$} & \multirow{2}{*}{$\begin{array}{c}\mathrm{NaBH}_{4}: \mathrm{Au} \\
(\mathrm{mol}: \mathrm{mol})\end{array}$} & \multicolumn{2}{|c|}{ Particle size (nm) } & \multirow{2}{*}{$\begin{array}{r}\text { Metal } \\
\text { loading } \\
\text { (wt\%) }\end{array}$} \\
\hline & & & & DLS & DF-STEM & \\
\hline 1 & 1 & $0.65: 1$ & $5: 1$ & $18.3 \pm 2.1$ & $15.1 \pm 6.2$ & 0.81 \\
\hline 2 & 2 & $0.65: 1$ & $5: 1$ & $6.8 \pm 2.0$ & $6.7 \pm 1.5$ & 0.87 \\
\hline 3 & 4 & $0.65: 1$ & $5: 1$ & $6.1 \pm 1.6$ & $7.0 \pm 2.0$ & 0.88 \\
\hline 4 & 6 & $0.65: 1$ & $5: 1$ & $5.5 \pm 1.7$ & $6.5 \pm 1.7$ & 0.94 \\
\hline 5 & 8 & $0.65: 1$ & $5: 1$ & $6.0 \pm 1.7$ & $5.4 \pm 0.9$ & 0.92 \\
\hline 6 & 24 & $0.65: 1$ & $5: 1$ & $5.9 \pm 1.7$ & $5.6 \pm 1.3$ & 0.94 \\
\hline $7^{\mathrm{a}}$ & 6 & $0.65: 1$ & $5: 1$ & $5.9 \pm 1.7$ & $7.0 \pm 1.9$ & 0.95 \\
\hline $8^{b}$ & 6 & $0.65: 1$ & $5: 1$ & $6.2 \pm 2.1$ & $7.4 \pm 2.2$ & 0.97 \\
\hline $9^{c}$ & 6 & $0.65: 1$ & $5: 1$ & $5.6 \pm 1.8$ & $6.4 \pm 1.5$ & 0.96 \\
\hline $10^{\mathrm{d}}$ & 6 & $0.65: 1$ & $5: 1$ & $5.2 \pm 1.6$ & $6.3 \pm 1.3$ & 0.94 \\
\hline $11^{\mathrm{e}}$ & 6 & $0.65: 1$ & $5: 1$ & $5.8 \pm 1.7$ & $7.5 \pm 2.5$ & 0.96 \\
\hline 12 & 6 & $0.65: 1$ & $1: 1$ & $50.9 \pm 3.0$ & $22.9 \pm 8.2$ & 0.41 \\
\hline 13 & 6 & $0.65: 1$ & $2.5: 1$ & $6.7 \pm 1.9$ & $9.0 \pm 2.8$ & 0.90 \\
\hline $14^{*}$ & 6 & $0.65: 1$ & $5: 1$ & $5.5 \pm 1.7$ & $6.5 \pm 1.7$ & 0.94 \\
\hline 15 & 6 & $0.65: 1$ & $7.5: 1$ & $16.1 \pm 2.2$ & $11.3 \pm 4.0$ & 0.92 \\
\hline 16 & 6 & $0: 1$ & $5: 1$ & $10.5 \pm 0.9$ & $14.5 \pm 8.7$ & 0.97 \\
\hline $17 *$ & 6 & $0.65: 1$ & $5: 1$ & $5.5 \pm 1.7$ & $6.5 \pm 1.7$ & 0.94 \\
\hline 18 & 6 & $1.3: 1$ & $5: 1$ & $7.0 \pm 1.3$ & $6.0 \pm 1.4$ & 0.93 \\
\hline
\end{tabular}

${ }^{\text {a }}$ Printed T-shape connection.

${ }^{\mathrm{b}}$ Printed Y-shape connection.

${ }^{\mathrm{c}}$ Printed I-shape connection.

d Printed helical reactor.

${ }^{\mathrm{e}}$ Printed plait-like reactor.

*Same catalyst as entry 4. 
Table 2 - Activity $\mathrm{k}_{\mathrm{App}}$ of batch and continuous derived $\mathrm{Au} / \mathrm{TiO}_{2}$ catalysts towards the reduction of various nitroarenes (NAR). Molar ratios of $(\mathrm{Au}+\mathrm{Pd}): \mathrm{NAR}: \mathrm{NaBH}_{4}$ are $1: 2.5: 250$.

\begin{tabular}{|c|c|c|c|}
\hline \multirow{2}{*}{ Substrate } & \multicolumn{2}{|c|}{$k_{A P P}\left[10^{3} s^{-1}\right]$} & \multirow{2}{*}{$\Delta \mathrm{kAPP}[\%]$} \\
\hline & Batch & Continuous & \\
\hline 4-NPH & 12.6 & 16.8 & 25 \\
\hline 4-NPH ${ }^{\mathrm{a}}$ & 24.4 & 28.9 & 16 \\
\hline 3-NPH & 8.9 & 10.3 & 14 \\
\hline 3-NPH ${ }^{\mathrm{a}}$ & 15.2 & 17.0 & 10 \\
\hline 2-NPH & 6.2 & 11.6 & 47 \\
\hline 2-NPH ${ }^{\mathrm{a}}$ & 11.0 & 14.1 & 22 \\
\hline NBZ & 4.7 & 9.4 & 50 \\
\hline $\mathrm{NBZ}^{\mathrm{a}}$ & 9.8 & 13.5 & 27 \\
\hline 4-NAL & 35.7 & 42.9 & 17 \\
\hline 4-NAL ${ }^{a}$ & 38.7 & 46.2 & 16 \\
\hline 4-NTL & 2.6 & 3.1 & 16 \\
\hline 4-NTL ${ }^{\mathrm{a}}$ & 4.6 & 5.6 & 18 \\
\hline 4-NBA & 7.4 & 8.4 & 12 \\
\hline $4-\mathrm{NBA}^{\mathrm{a}}$ & 14.9 & 15.9 & 6 \\
\hline
\end{tabular}

${ }^{\text {a }}$ The bimetallic $\mathrm{AuPd} / \mathrm{TiO}_{2}$ catalyst was also tested for this reaction. 
Table 3 - Activity and selectivity of batch $\mathrm{AuPd} / \mathrm{TiO}_{2}$, continuous $\mathrm{AuPd} / \mathrm{TiO}_{2}$ and $\mathrm{Au} @ \mathrm{Pd} / \mathrm{TiO} 2$ catalysts towards the cinnamaldehyde hydrogenation reaction. Reaction conditions: $100{ }^{\circ} \mathrm{C}, 1 \mathrm{bar}$ $\mathrm{H}_{2}$, catalyst amount $50 \mathrm{mg}$ and CAL $4 \mathrm{mmol}$ in $5 \mathrm{~mL}$ of toluene. Substrate and products: cinnamaldehyde (CAL), hydrocinnamaldehyde (HCAL), cinnamyl alcohol (COH), hydrocinnamyl alcohol $(\mathrm{HCOH})$ and phenylpropane (PPR).

\begin{tabular}{|c|c|c|c|c|c|}
\hline \multirow{2}{*}{ Catalyst } & \multirow{2}{*}{$\begin{array}{c}\text { Conversion } \\
{[\%]}\end{array}$} & \multicolumn{4}{|c|}{ Selectivity [\%] } \\
\hline & & HCAL & $\mathrm{COH}$ & НСОН & PPR \\
\hline $\mathrm{AuPd} / \mathrm{TiO}_{2}$-batch & 52 & 40 & 6 & 52 & 2 \\
\hline $\mathrm{AuPd} / \mathrm{TiO}_{2}$-continuous & 55 & 55 & 1 & 41 & 3 \\
\hline $\mathrm{Au} @ \mathrm{Pd} / \mathrm{TiO}_{2}$ & 68 & 63 & 1 & 34 & 2 \\
\hline
\end{tabular}

